\title{
Cariprazine in Youth with Bipolar and Psychotic Disorders: A Retrospective Chart Review
}

\author{
Ethan A. Poweleit, BS, ${ }^{1}$ Michaela Colestock, MS, ${ }^{2}$ Eashwar C. Kantemneni, ${ }^{3}$ Jeffrey R. Strawn, MD, ${ }^{3}$ \\ Luis R. Patino, MD, ${ }^{3}$ Melissa P. DelBello, MD, MS, ${ }^{3}$ and Laura B. Ramsey, $\mathrm{PhD}^{4}$
}

\begin{abstract}
Objective: To examine the potential effectiveness and tolerability of cariprazine in pediatric bipolar and psychotic disorders. Methods: We retrospectively reviewed the electronic health records of patients $<21$ years of age prescribed cariprazine to treat bipolar and psychotic disorders. Adverse effects, tolerability, therapeutic response (Clinical Global ImpressionImprovement [CGI-I]), and severity of illness (Clinical Global Impression-Severity [CGI-S]) were determined through manual chart review.

Results: We identified 16 patients aged 6-20 years who were treated with cariprazine (initial dose: $1.5 \mathrm{mg} /$ day, interquartile range [IQR], 1.5-1.5; endpoint dose: $3 \mathrm{mg} / \mathrm{day}, \mathrm{IQR}, 1.5-4.5$ ). No serious adverse events were reported, but the most commonly reported side effect was weight gain $(n=3,19 \%)$. Of the 14 patients for whom baseline and endpoint body mass index (BMI) data were available, neither changes in BMI ( $p=0.391 ; 0.54 \mathrm{~kg} / \mathrm{m}^{2}, \mathrm{IQR},-0.33$ to 1.38 ) nor BMI percentile ( $p=0.71 ; 0.36 \%$, IQR, -0.49 to 3.97 ) significantly differed between baseline and endpoint. However, patients receiving $\geq 4.5 \mathrm{mg} /$ day had a significantly greater BMI increases during the course of treatment compared with those receiving $\leq 3 \mathrm{mg} /$ day $\left(p=0.034 ;-1.14 \mathrm{~kg} / \mathrm{m}^{2}, \mathrm{IQR},-3.65\right.$ to $\left.0.53 \mathrm{vs.} 1.01 \mathrm{~kg} / \mathrm{m}^{2}, \mathrm{IQR}, 0.17-4.88\right)$. CGI-S scores $(p=0.016 ; 4.5$, IQR, $4-5$ vs. 4, IQR, 3-4) significantly differed from baseline to endpoint. The response rate was $44 \%(n=7 / 16)$, with responders being prescribed higher doses ( $p=0.005 ; 6 \mathrm{mg}$ /day, IQR, 4.875-6 vs. $3 \mathrm{mg} /$ day, IQR, 3-4.125).

Conclusions: Cariprazine may be well tolerated and effective for pediatric bipolar and psychotic disorders; however, compared with higher doses, total daily doses $\leq 3 \mathrm{mg}$ /day appear to be more tolerable. Prospective controlled studies to further evaluate cariprazine in youth are needed.
\end{abstract}

Keywords: cariprazine, antipsychotic, bipolar disorder, psychosis, weight gain, body mass index (BMI), pediatric

\section{Introduction}

$\mathbf{R}$ ANDOMIZED CONTROLled TRIALS have established the efficacy of multiple dopamine-serotonin receptor antagonists (DSRAs) - formerly designated as second-generation antipsychotics - in youth with psychosis, mania, irritability associated with autism spectrum disorders, and Tourette's disorder (McCracken et al. 2002; Findling et al. 2008; Kumra et al. 2008; Fraguas et al. 2011; Sallee et al. 2017). As a result, these medications are increasingly prescribed to treat bipolar or psychotic disorders in youth (Olfson et al. 2006, 2012). Although DSRAs offer advantages over conventional dopamine receptor antagonists
(DRAs; e.g., haloperidol) — formerly designated as first-generation antipsychotics - such as fewer extrapyramidal symptoms (Correll et al. 2004), most DSRAs have been associated with weight gain and adverse metabolic effects in both adults (Leucht et al. 2009) and youth (Correll et al. 2009; Krill et al. 2014). Therefore, significant concern regarding the increase use of DSRAs in youth remains, particularly because these patients may be more susceptible to DSRA-related metabolic side effects (Kumra et al. 2008; Correll et al. 2009).

While evidence supports DSRA efficacy in youth, many of these agents are only approved by the United States Food and Drug Administration (FDA) for use in treating adults and are prescribed

\footnotetext{
${ }^{1}$ Division of Research in Patient Services, Cincinnati Children's Hospital Medical Center, Cincinnati, Ohio, USA.

${ }^{2}$ Molecular, Cellular, and Biochemical Pharmacology, Department of Pharmacology and Systems Physiology, University of Cincinnati, Cincinnati, Ohio, USA.

${ }^{3}$ Department of Psychiatry \& Behavioral Neuroscience, University of Cincinnati, Cincinnati, Ohio, USA.

${ }^{4}$ Divisions of Research in Patient Services and Clinical Pharmacology, Department of Pediatrics, Cincinnati Children's Hospital Medical Center and University of Cincinnati College of Medicine, Cincinnati, Ohio, USA.

Funding: No funding was received for this article.
} 
"off-label" in pediatric patients. Namely one medication in this class - cariprazine - is only FDA-approved for adults experiencing acute manic or mixed episodes associated with bipolar disorder, depressive episodes associated with bipolar disorder (bipolar depression), and schizophrenia (Vraylar 2019). Cariprazine, a dopamine and serotonin receptor partial agonist and antagonist (neuroscience-based nomenclature), has a complex, yet unique, pharmacodynamic and pharmacokinetic profile that sets it apart from other DSRAs. Pharmacodynamically, it is a dopamine $\mathrm{D}_{2}$ and $D_{3}$ receptor partial agonist that preferentially binds to $D_{3}$ receptors (Delcourte et al. 2018). Furthermore, it antagonizes 5-HT $2 \mathrm{~A}, 5-$ $\mathrm{HT}_{2 \mathrm{~B}}, 5-\mathrm{HT}_{2 \mathrm{C}}$, and histamine $\mathrm{H}_{1}$ receptors. It is also a partial agonist for 5-HT $1 \mathrm{~A}$ receptors (Kiss et al. 2010). Pharmacokinetically, cariprazine is metabolized primarily by the hepatic, polymorphic cytochrome P450 enzymes CYP3A4 and, to a lesser extent, CYP2D6 (Citrome 2013). It also has two equipotent metabolitesdesmethyl-cariprazine and didesmethyl-cariprazine-of which didesmethyl-cariprazine has a half-life of 1-3 weeks in adults (Campbell et al. 2017).

Commonly reported adverse events include extrapyramidal symptoms, headaches, gastrointestinal symptoms (i.e., nausea, vomiting, abdominal pain, stomachache, constipation), insomnia, and weight gain (Vraylar 2019). One mechanism of antipsychoticinduced weight gain could be through affinity for the $\mathrm{H}_{1}$ receptor (Kroeze et al. 2003), for which cariprazine has moderate affinity. However, because cariprazine preferentially binds to $D_{3}$ receptors and has moderate-to-low affinity for histamine $\mathrm{H}_{1}$ and 5- $\mathrm{HT}_{2 \mathrm{C}}$ receptors, it may have fewer clinically relevant adverse effects on metabolic variables in adults (Kiss et al. 2010; Citrome 2013). Nevertheless, despite lower rates of weight gain compared with other dopamine serotonin receptor antagonists (e.g., risperidone, quetiapine), cariprazine-associated weight gain has been reported in adults with schizophrenia (Durgam et al. 2017b; Cutler et al. 2018).

Numerous studies reveal that cariprazine is effective in treating adults with bipolar disorder (Calabrese et al. 2015; Durgam et al. 2015b, 2016b, 2017; Sachs et al. 2015; Earley et al. 2019), schizophrenia (Durgam et al. 2014, 2015a, 2016c, 2017; Kane et al. 2015), and major depressive disorder (Durgam et al. 2016a; Vieta et al. 2019). However, to the best of our knowledge, there have been no reports of the safety or effectiveness of cariprazine in pediatric patients.

As reviewed by Campbell et al. (2017), with minimal treatmentrelated adverse effects, once-daily dosing, shorter titration periods, and avoidance of other drugs metabolized by CYP3A4 and/or CYP2D6, cariprazine could be a novel, well-tolerated, and efficacious treatment for pediatric bipolar and psychotic disorders. With these considerations in mind, we retrospectively evaluated the electronic health record (EHR) to explore the effectiveness and tolerability of cariprazine treatment in pediatric patients diagnosed with bipolar and psychotic disorders. To the best of our knowledge, this is the first description of cariprazine in youth.

\section{Methods}

The EHR data from patients who were 6-20 years old, treated at Cincinnati Children's Hospital Medical Center (CCHMC), prescribed cariprazine, and returned for a follow-up visit in the CCHMC-based outpatient psychiatry clinic were extracted and reviewed $(n=16)$. Demographic and clinical information, including age, sex, race, primary diagnoses, comorbid conditions, height, weight, body mass index (BMI), cariprazine doses, and pharmacogenetic testing results (e.g., CYP2D6), was included in the chart review. Diagnoses of bipolar disorder, type I, type II, or not oth- erwise specified (NOS) and other mood disorders were confirmed by a child and adolescent psychiatrist (M.P.D., L.R.P., and J.R.S.). The cariprazine treatment period was defined as the duration a patient was prescribed cariprazine between baseline (the initial visit when cariprazine was first prescribed) and endpoint (the first visit at which cariprazine was discontinued, the last visit before a patient was lost to follow-up, or the date of the last chart review). The maximum cariprazine dose was the highest dose $(\mathrm{mg} /$ day) prescribed during the treatment period. Concomitant use of 9 DRAs (e.g., chlorpromazine, fluphenazine, haloperidol, loxapine, perphenazine, pimozide, thioridazine, thiothixene, and trifluoperazine), 11 DSRAs (e.g., aripiprazole, asenapine, clozapine, brexpiprazole, iloperidone, lurasidone, olanzapine, paliperidone, quetiapine, risperidone, and ziprasidone), and lithium was assessed for any overlap with the cariprazine treatment period.

Response to cariprazine was assessed with Clinical Global Impression-Improvement (CGI-I) scores, whereas severity of symptoms was assessed with Clinical Global Impression-Severity (CGI-S) scores (Guy 1976). A CGI-I score of either "1" or " 2 " indicated that the patient was responding to cariprazine treatment. The time to response was the total number of days from the start of cariprazine treatment to the first incidence of a CGI-I score of 1 or 2 , whereas the response dose was the cariprazine dose a patient was receiving at the first CGI-I score of "1" or "2." CGI-I and CGI-S scores were mostly available in the EHR at baseline and endpoint of the cariprazine treatment period, but additional CGI-S scores were determined through subsequent chart review by a child and adolescent psychiatrist. Side effects (i.e., aggression, extrapyramidal symptoms, gastrointestinal symptoms, headaches, insomnia, panic attacks, prolonged QT, sedation, suicidality, and weight gain) associated with cariprazine treatment and the reason for discontinuation were determined through manual review of the clinician notes at each visit during the cariprazine treatment period.

CYP2D6 pharmacogenetic testing results were obtained either from our institution $(n=11)$ (Ramsey et al. 2019) or from an external pharmacogenetic testing service $(n=1)$. The external pharmacogenetic testing service provided a different interpretation regarding the activity level of the allelic combination and the conversion to metabolizer phenotype, so the one patient's metabolizer status was reinterpreted to match the Clinical Pharmacogenetics Implementation Consortium's interpretation.

After testing for normality using the Shapiro-Wilk test, Wilcoxon signed-rank tests examined differences in BMI and BMI percentile between measurements at the start and end of cariprazine therapy, as well as changes in CGI-S scores from baseline to endpoint. Secondary outcome measures included the effects of cariprazine dosing on the rate of response (i.e., CGI-I score $\leq 2$ ) and changes in BMI, as well as if the duration of cariprazine treatment of responders differed from nonresponders. One-way analysis of variance test for linear trend and unpaired $t$-tests assessed for differences with CYP2D6 metabolizer status and sex, respectively. Statistical tests were performed in Prism 8 for Windows (GraphPad, La Jolla, CA). Additionally, multivariate generalized linear regression models that included concomitant medications were performed in $R$ version 3.5.1 for each significant finding (i.e., BMI, dosing) to control for the possibility that concomitant medications could be contributing to treatmentrelated adverse events and/or efficacy. Results are reported with the median and interquartile range (IQR), and findings were considered statistically significant at a threshold of 0.05 . Finally, this study was approved by the institutional review board at our institution. 


\section{Results}

Sixteen children and adolescents (aged 6-20 years) were included in this retrospective sample (Table 1). The median starting dose of cariprazine was $1.5 \mathrm{mg} /$ day (IQR, 1.5-1.5) and the endpoint dose was $3 \mathrm{mg} /$ day (IQR, 1.5-4.5). There were more girls than boys included in the study $(n=11)$, and the girls were significantly older than the boys $(p=0.018)$. Only 3 patients $(19 \%)$ received cariprazine monotherapy compared with 13 patients $(81 \%)$ who were treated with concomitant antipsychotic medication and/or lithium. Cariprazine was prescribed for the treatment of several psychiatric disorders, with 12 patients $(75 \%)$ receiving cariprazine to treat bipolar disorder, type I $(n=7,44 \%)$, type II $(n=3,19 \%)$, or NOS $(n=2,12.5 \%)$, and the other 4 patients $(25 \%)$ being treated for depressive disorder $(n=2,13 \%)$ and intermittent explosive disor$\operatorname{der}(n=2,13 \%)$. Of the 16 patients, $8(50 \%)$ discontinued cariprazine therapy, with 3 (19\%) withdrawing due to inefficacy and 1 (6\%) withdrawing due to adverse side effects (e.g., weight gain). The other four patients who discontinued cariprazine did not have a discernible reason specified in the chart.

Side effects were reported in $37.5 \%$ of patients $(n=6 / 16)$, with weight gain being the most commonly reported side effect $(n=3$, $19 \%)$. Of these three patients, two (67\%) were on concomitant psychotropic medications (e.g., aripiprazole, ziprasidone). The second most common side effect was sedation $(n=2,12 \%)$, followed by gastrointestinal symptoms $(n=1,6 \%)$, insomnia $(n=1$, $6 \%)$, panic attacks $(n=1,6 \%)$, and prolonged QT $(n=1,6 \%)$.

Table 1. Demographic and Clinical Characteristics of Cariprazine-Treated Youth

\begin{tabular}{|c|c|}
\hline Characteristic & $\begin{array}{c}\text { Cariprazine cohort } \\
(\mathrm{n}=16)\end{array}$ \\
\hline Age (years), median (range) & $15(6-20)$ \\
\hline$>12, n(\%)$ & $14(88)$ \\
\hline$\leq 12, n(\%)$ & $2(12)$ \\
\hline \multicolumn{2}{|l|}{ Sex, $n(\%)$} \\
\hline Girls & $11(69)$ \\
\hline Boys & $5(31)$ \\
\hline \multicolumn{2}{|l|}{ Race, $n(\%)$} \\
\hline Black & $1(6)$ \\
\hline Other & $1(6)$ \\
\hline White & $14(88)$ \\
\hline \multicolumn{2}{|l|}{ Primary diagnosis, $n(\%)$} \\
\hline Bipolar (type I, type II, NOS) & $12(75)$ \\
\hline Depressive disorder & $2(13)$ \\
\hline Intermittent explosive disorder & $2(13)$ \\
\hline \multicolumn{2}{|l|}{ Concomitant medications, $n(\%)$} \\
\hline DRAs & $1(6)$ \\
\hline DSRAs & 7 (44) \\
\hline DRAs+DSRAs & $3(19)$ \\
\hline Lithium & $5(31)$ \\
\hline $\begin{array}{l}\text { Duration of cariprazine treatment (days), } \\
\text { median (range) }\end{array}$ & $115.5(30-485)$ \\
\hline Cariprazine dose (mg/day), median (range) & $3.75(1.5-6)$ \\
\hline \multicolumn{2}{|l|}{ Discontinuation reason, $n(\%)$} \\
\hline Total & $8(50)$ \\
\hline Ineffective & $3(19)$ \\
\hline Side effects & $1(6)$ \\
\hline Unknown & $4(25)$ \\
\hline
\end{tabular}

DRAs, dopamine receptor antagonists; DSRAs, dopamine-serotonin receptor antagonists; $n$, number; NOS, not otherwise specified.

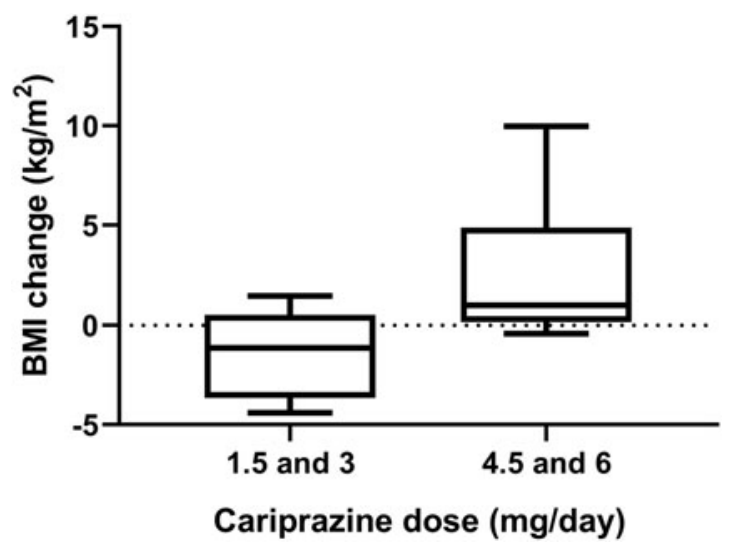

FIG. 1. Patients who received cariprazine doses $\geq 4.5 \mathrm{mg} /$ day during the treatment period experienced a greater increase in BMI compared with those who were prescribed $\leq 3 \mathrm{mg} /$ day of cariprazine ( $p=0.034$, unpaired $t$-test). The median, lower, and upper quartiles, and minimum and maximum values are represented by the box and whiskers plot. BMI, body mass index.

BMI and its percentile were available for 14 patients $(87.5 \%)$. During treatment, BMI increased $0.54 \mathrm{~kg} / \mathrm{m}^{2}(p=0.391$; IQR, -0.33 to 1.38 ) and ranged from -4.41 to $9.98 \mathrm{~kg} / \mathrm{m}^{2}$, whereas BMI percentile increased $0.36 \%$ ( $p=0.71$; IQR, -0.49 to 3.97$)$ and ranged from $-57.27 \%$ to $11.73 \%$. Neither sex nor CYP2D6 metabolizer phenotype influenced change in BMI or BMI percentile. Patients who received a maximum cariprazine dose of $\geq 4.5 \mathrm{mg} /$ day experienced a greater increase in BMI from baseline $\left(-1.14 \mathrm{~kg} / \mathrm{m}^{2}\right.$; IQR, -3.65 to 0.53 ) than those who were prescribed $\leq 3 \mathrm{mg} /$ day $\left(1.01 \mathrm{~kg} / \mathrm{m}^{2}\right.$; IQR, $\left.0.17-4.88\right)$ over the course of cariprazine treatment $(p=0.034$; Fig. 1$)$.

The median CGI-S scores at baseline and endpoint were 5 (IQR, 4-5) and 4 (IQR, 3-4), respectively; additionally, the CGI-S scores significantly improved from baseline to endpoint $(p=0.016)$. Seven of the 16 patients $(44 \%)$ responded (i.e., CGI-I score $\leq 2)$ to cariprazine treatment. The duration of cariprazine treatment did not differ between responders and nonresponders ( $p=0.60 ; 246$ days; IQR, 20-360 vs. 122 days; IQR, 69-259.5). However, responders were prescribed higher cariprazine doses during their treatment period than nonresponders ( $p=0.008 ; 6 \mathrm{mg} /$ day; IQR, $4.5-6 \mathrm{vs}$. $3 \mathrm{mg} / \mathrm{day}$; IQR, 1.5-3.75). Five of the seven responders experienced an increase in BMI (range, -0.42 to $5.54 \mathrm{~kg} / \mathrm{m}^{2}$ ) during cariprazine therapy. These seven patients were also all taking cariprazine adjunctively with other psychotropic medications (range, 1-5 medications). Finally, three of the seven responders discontinued cariprazine (reason unknown or due to ineffectiveness) compared with five of the nine nonresponders who discontinued cariprazine (reason unknown, due to ineffectiveness, or adverse effects).

\section{Discussion}

In this retrospective chart review of the tolerability and efficacy of cariprazine in pediatric patients diagnosed with bipolar and psychotic disorders, we found that differences in cariprazine dosing might explain the observed increase in BMI and efficacy of this DSRA. Overall, the findings presented herein suggest that cariprazine may be a well-tolerated, effective, and adjunctive medication for treating bipolar and psychotic disorders in children and adolescents. 
Cariprazine-associated side effects were consistent with those observed in adults with bipolar disorder (Durgam et al. 2016; Earley et al. 2019; Vraylar 2019). Specifically, weight gain was the most common side effect, which is consistent with prospective trials of cariprazine in adults (Durgam et al. 2017; Cutler et al. 2018) and with DSRAs in children and adolescents (Correll et al. 2009; Krill et al. 2014). Despite this, BMI and BMI percentile at baseline and endpoint did not significantly differ, a finding that is potentially consistent with typical growth and development in our cohort. Furthermore, BMI and BMI percentile were not associated with sex, despite girls being more susceptible to DSRA-induced weight gain (Gebhardt et al. 2009; Seeman 2009). This could be due to our small sample size, the predominance of girls, prior concomitant medication use (e.g., switching from a medication with high risk of metabolic liability to one with a lower risk), adherence, individual differences in diet and lifestyle, as well as pharmacodynamic factors (e.g., histamine $\mathrm{H}_{1}$ and $5-\mathrm{HT}_{2 \mathrm{C}}$ receptors) (Kiss et al. 2010). CYP2D6 metabolizer phenotype did not influence BMI, which is consistent with CYP2D6 playing only a minor role in cariprazine metabolism (Citrome 2013). We did, however, observe that the median change in BMI from baseline was associated with cariprazine dose, where patients receiving a maximum dose of 4.5 or $6 \mathrm{mg} /$ day of cariprazine had a larger increase in BMI compared with those prescribed 1.5 or $3 \mathrm{mg} /$ day of cariprazine. This suggests that youth receiving higher doses (i.e., $\geq 4.5 \mathrm{mg} /$ day) of cariprazine may be at a higher risk of BMI increase than those receiving lower doses. To the best of our knowledge, this is the first study to demonstrate that increases in BMI are associated with higher cariprazine doses. Long-term studies with a larger patient cohort to better characterize the effects of cariprazine dose on BMI are warranted.

In alignment with prior studies assessing the effectiveness of cariprazine for adult bipolar disorders, baseline and endpoint CGI$\mathrm{S}$ scores significantly differed from one another (Calabrese et al. 2015; Durgam et al. 2015, 2016, 2017; Sachs et al. 2015). Furthermore, it should be noted that prior reports suggest that clinicians often utilize newer treatments in patients who have failed prior first- and second-line interventions (Hui Poon et al. 2015). Thus, the sample examined herein may be enriched for treatment resistance, although changes are minor.

Of our patient sample, $44 \%$ responded to cariprazine therapy. Responders were prescribed higher doses compared with nonresponders, thereby suggesting cariprazine, especially as an adjunctive therapy, may be effective for pediatric bipolar and psychotic disorders. This is consistent with cariprazine trials in adults with major depressive disorder (Durgam et al. 2016; Vieta et al. 2019). Additionally, a majority of patients had increases in BMI during treatment, suggesting that increases in BMI may be dose- (or exposure-) dependent. This finding highlights the need to use the lowest effective cariprazine dose to potentially avoid or minimize metabolic liability.

While this is the first examination of cariprazine in pediatric patients, there are several limitations. First, because of the retrospective nature of the study, we lack data for variables that could influence cariprazine tolerability and efficacy (e.g., CYP3A4 genotype/phenotype). Second, the rationale for prescribing cariprazine is, at times, difficult to discern from retrospective records. Third, patients may have experienced prior medication trials, and thus, our population could be enriched for treatment resistance. Fourth, our sample was small $(n=16)$ and its homogeneity may complicate generalizability. Fifth, multiple factors (e.g., concomitant medications, comorbidity) may confound our ability to examine side effects, BMI, response, and remission. However, all significant values related to tolerability and efficacy were confirmed using multivariate generalized linear regression models that controlled for polypharmacy.

\section{Conclusions}

Adjunctive cariprazine was generally well tolerated in pediatric bipolar and psychotic disorders and, for many patients, reduced symptoms (i.e., improved CGI-S scores from baseline to the last recorded measure). However, BMI change from baseline was associated with higher cariprazine doses (i.e., $\geq 4.5 \mathrm{mg} /$ day), with these patients being at a higher risk for increases in BMI. These findings underscore the importance of closely monitoring weight and BMI in youth treated with higher cariprazine doses. Further research examining the effects of dose on weight gain, BMI, and efficacy in youth is necessary.

\section{Clinical Significance}

Adjunctive cariprazine may have a role in the treatment of some pediatric patients with bipolar and psychotic disorders, particularly in those who failed prior psychopharmacologic interventions (i.e., "treatment resistant" patients). When using cariprazine in pediatric patients, clinicians should monitor side effects, particularly at higher doses, and should be vigilant regarding the potential for lateoccurring adverse events due to the long half-life of cariprazine and its metabolites.

\section{Disclosures}

Dr. J.R.S. has received research support from the National Institutes of Health (NIMH/NIEHS/NICHD), Patient-Centered Outcomes Research Institute, as well as Allergan, Otsuka, and Neuronetics. He has received material support from and provided consultation to Myriad Genetics and receives royalties from the publication of two texts (Springer). Dr. J.R.S. serves as an author for UpToDate, an Associate Editor for Current Psychiatry, and has received honoraria from CMEology. Dr. M.P.D. receives research support from Acadia, Allergan, Janssen, Johnson and Johnson, Lundbeck, Myriad Genetics, the National Institutes of Health (NIMH), Otsuka, the Patient-Centered Outcomes Research Institute, Pfizer, Shire, Sunovion, and Supernus. She is also a consultant, on the advisory board, or has received honoraria for speaking for Alkermes, Allergan, Assurex, CMEology, Janssen, Johnson and Johnson, Lundbeck, Medscape, Neuronetics, Otsuka, Pfizer, Sunovion, and Supernus. Dr. L.R.P. receives research support from Acadia, Allergen, Janssen, Johnson and Johnson, Lundbeck, Otsuka, Pfizer, Sunovion, and Supernus. Dr. L.B.R. has received research support from the National Institutes of Health (NICHD) and BTG, International Ltd. The remaining authors report no financial conflicts of interest.

\section{References}

Calabrese JR, Keck PE, Jr., Starace A, Lu K, Ruth A, Laszlovszky I, Nemeth G, Durgam S: Efficacy and safety of low- and high-dose cariprazine in acute and mixed mania associated with bipolar I disorder: A double-blind, placebo-controlled study. J Clin Psychiatry 76:284-292, 2015.

Campbell RH, Diduch M, Gardner KN, Thomas C: Review of cariprazine in management of psychiatric illness. Ment Health Clin 7: 221-229, 2017.

Citrome L: Cariprazine: Chemistry, pharmacodynamics, pharmacokinetics, and metabolism, clinical efficacy, safety, and tolerability. Expert Opin Drug Metab Toxicol 9:193-206, 2013. 
Correll CU, Leucht S, Kane JM: Lower risk for tardive dyskinesia associated with second-generation antipsychotics: A systematic review of 1-year studies. Am J Psychiatry 161:414-425, 2004.

Correll CU, Manu P, Olshanskiy V, Napolitano B, Kane JM, Malhotra AK: Cardiometabolic risk of second-generation antipsychotic medications during first-time use in children and adolescents. JAMA 302:1765-1773, 2009.

Cutler AJ, Durgam S, Wang Y, Migliore R, Lu K, Laszlovszky I, Nemeth G: Evaluation of the long-term safety and tolerability of cariprazine in patients with schizophrenia: Results from a 1-year open-label study. CNS Spectr 23:39-50, 2018.

Delcourte S, Ashby CR, Jr., Rovera R, Kiss B, Adham N, Farkas B, Haddjeri N: The novel atypical antipsychotic cariprazine demonstrates dopamine D2 receptor-dependent partial agonist actions on rat mesencephalic dopamine neuronal activity. CNS Neurosci Ther 24:1129-1139, 2018.

Durgam S, Cutler AJ, Lu K, Migliore R, Ruth A, Laszlovszky I, Nemeth G, Meltzer HY: Cariprazine in acute exacerbation of schizophrenia: A fixed-dose, phase 3, randomized, double-blind, placebo- and active-controlled trial. J Clin Psychiatry 76:e1574e1582, 2015a.

Durgam S, Earley W, Guo H, Li D, Nemeth G, Laszlovszky I, Fava M, Montgomery SA: Efficacy and safety of adjunctive cariprazine in inadequate responders to antidepressants: A randomized, doubleblind, placebo-controlled study in adult patients with major depressive disorder. J Clin Psychiatry 77:371-378, 2016a.

Durgam S, Earley W, Lipschitz A, Guo H, Laszlovszky I, Nemeth G, Vieta E, Calabrese JR, Yatham LN: An 8-week randomized, double-blind, placebo-controlled evaluation of the safety and efficacy of cariprazine in patients with bipolar I depression. Am J Psychiatry 173:271-281, 2016b.

Durgam S, Earley W, Lu K, Nemeth G, Laszlovszky I, Volk S, Litman RE: Global improvement with cariprazine in the treatment of bipolar I disorder and schizophrenia: A pooled post hoc analysis. Int J Clin Pract 71:e13037, 2017a.

Durgam S, Greenberg WM, Li D, Lu K, Laszlovszky I, Nemeth G, Migliore R, Volk S: Safety and tolerability of cariprazine in the long-term treatment of schizophrenia: Results from a 48-week, single-arm, open-label extension study. Psychopharmacology (Berl) 234:199-209, 2017b.

Durgam S, Litman RE, Papadakis K, Li D, Nemeth G, Laszlovszky I: Cariprazine in the treatment of schizophrenia: A proof-of-concept trial. Int Clin Psychopharmacol 31:61-68, 2016c.

Durgam S, Starace A, Li D, Migliore R, Ruth A, Nemeth G, Laszlovszky I: An evaluation of the safety and efficacy of cariprazine in patients with acute exacerbation of schizophrenia: A phase II, randomized clinical trial. Schizophr Res 152:450-457, 2014.

Durgam S, Starace A, Li D, Migliore R, Ruth A, Nemeth G, Laszlovszky I: The efficacy and tolerability of cariprazine in acute mania associated with bipolar I disorder: A phase II trial. Bipolar Disord 17:63-75, 2015b.

Earley W, Victoria Burgess M, Rekeda L, Dickinson R, Szatmari B, Nemeth G, McIntyre RS, Sachs GS, Yatham LN: Cariprazine Treatment of Bipolar Depression: A randomized double-blind placebo-controlled phase 3 study. Am J Psychiatry 176:439-448, 2019.

Findling RL, Robb A, Nyilas M, Forbes RA, Jin N, Ivanova S, Marcus R, McQuade RD, Iwamoto T, Carson WH: A multiple-center, randomized, double-blind, placebo-controlled study of oral aripiprazole for treatment of adolescents with schizophrenia. Am J Psychiatry 165:1432-1441, 2008.

Fraguas D, Correll CU, Merchan-Naranjo J, Rapado-Castro M, Parellada M, Moreno C, Arango C: Efficacy and safety of second- generation antipsychotics in children and adolescents with psychotic and bipolar spectrum disorders: Comprehensive review of prospective head-to-head and placebo-controlled comparisons. Eur Neuropsychopharmacol 21:621-645, 2011.

Gebhardt S, Haberhausen M, Heinzel-Gutenbrunner M, Gebhardt N, Remschmidt H, Krieg JC, Hebebrand J, Theisen FM: Antipsychotic-induced body weight gain: Predictors and a systematic categorization of the long-term weight course. J Psychiatr Res 43:620-626, 2009.

Guy W: ECDEU Assessment Manual for Psychopharmacology. Rockville, MD: U.S. Department of Health, Education, and Welfare, Public Health Service, Alcohol, Drug Abuse, and Mental Health Administration, National Institute of Mental Health, Pscyhopharmacology Research Branch, Division of Extramural Research Programs; 1976.

Hui Poon S, Sim K, Baldessarini RJ: Pharmacological approaches for treatment-resistant bipolar disorder. Curr Neuropharmacol 13:592604, 2015.

Kane JM, Zukin S, Wang Y, Lu K, Ruth A, Nagy K, Laszlovszky I, Durgam S: Efficacy and safety of cariprazine in acute exacerbation of schizophrenia: Results from an international, phase III clinical trial. J Clin Psychopharmacol 35:367-373, 2015.

Kiss B, Horvath A, Nemethy Z, Schmidt E, Laszlovszky I, Bugovics G, Fazekas K, Hornok K, Orosz S, Gyertyan I, Agai-Csongor E, Domany G, Tihanyi K, Adham N, Szombathelyi Z: Cariprazine (RGH-188), a dopamine $\mathrm{D}(3)$ receptor-preferring, $\mathrm{D}(3) / \mathrm{D}(2)$ dopamine receptor antagonist-partial agonist antipsychotic candidate: In vitro and neurochemical profile. J Pharmacol Exp Ther 333:328340, 2010.

Krill RA, Kumra S: Metabolic consequences of second-generation antipsychotics in youth: Appropriate monitoring and clinical management. Adolesc Health Med Ther 5:171-182, 2014.

Kroeze WK, Hufeisen SJ, Popadak BA, Renock SM, Steinberg S, Ernsberger P, Jayathilake K, Meltzer HY, Roth BL: H1-histamine receptor affinity predicts short-term weight gain for typical and atypical antipsychotic drugs. Neuropsychopharmacology 28:519526, 2003.

Kumra S, Oberstar JV, Sikich L, Findling RL, McClellan JM, Vinogradov S, Charles Schulz S: Efficacy and tolerability of second-generation antipsychotics in children and adolescents with schizophrenia. Schizophr Bull 34:60-71, 2008.

Leucht S, Corves C, Arbter D, Engel RR, Li C, Davis JM: Secondgeneration versus first-generation antipsychotic drugs for schizophrenia: A meta-analysis. Lancet 373:31-41, 2009.

McCracken JT, McGough J, Shah B, Cronin P, Hong D, Aman MG, Arnold LE, Lindsay R, Nash P, Hollway J, McDougle CJ, Posey D, Swiezy N, Kohn A, Scahill L, Martin A, Koenig K, Volkmar F, Carroll D, Lancor A, Tierney E, Ghuman J, Gonzalez NM, Grados M, Vitiello B, Ritz L, Davies M, Robinson J, McMahon D; Research Units on Pediatric Psychopharmacology Autism Network: Risperidone in children with autism and serious behavioral problems. N Engl J Med 347:314-321, 2002.

Olfson M, Blanco C, Liu L, Moreno C, Laje G: National trends in the outpatient treatment of children and adolescents with antipsychotic drugs. Arch Gen Psychiatry 63:679-685, 2006.

Olfson M, Blanco C, Liu SM, Wang S, Correll CU: National trends in the office-based treatment of children, adolescents, and adults with antipsychotics. Arch Gen Psychiatry 69:1247-1256, 2012.

Ramsey LB, Prows CA, Zhang K, Saldana SN, Sorter MT, Pestian JP, Wenstrup RJ, Vinks AA, Glauser TA: Implementation of pharmacogenetics at Cincinnati Children's Hospital Medical Center: Lessons learned over 14 years of personalizing medicine. Clin Pharmacol Ther 105:49-52, 2019. 
Sachs GS, Greenberg WM, Starace A, Lu K, Ruth A, Lszlovszky I, Nemeth G, Durgam S: Cariprazine in the treatment of acute mania in bipolar I disorder: A double-blind, placebo-controlled, phase III trial. J Affect Disord 174:296-302, 2015.

Sallee F, Kohegyi E, Zhao J, McQuade R, Cox K, Sanchez R, van Beek A, Nyilas M, Carson W, Kurlan R: Randomized, double-blind, placebo-controlled trial demonstrates the efficacy and safety of oral aripiprazole for the treatment of Tourette's disorder in children and adolescents. J Child Adolesc Psychopharmacol 27:771-781, 2017.

Seeman MV: Secondary effects of antipsychotics: Women at greater risk than men. Schizophr Bull 35:937-948, 2009.

Vieta E, Earley WR, Burgess MV, Durgam S, Chen C, Zhong Y, Barabassy A, Nemeth G: Long-term safety and tolerability of cariprazine as adjunctive therapy in major depressive disorder. Int Clin Psychopharmacol 34:76-83, 2019.
Vraylar: Vraylar (cariprazine) [package insert]. Dublin, IE, Allergen, 2019. https://www.accessdata.fda.gov/drugsatfda_docs/label/2019/ 204370s006lbl.pdf Accessed December 4, 2019.

Address correspondence to:

Laura B. Ramsey, PhD

Divisions of Research in Patient Services and Clinical Pharmacology

Department of Pediatrics

Cincinnati Children's Hospital Medical Center

3333 Burnet Avenue, MLC 6018

Cincinnati, $\mathrm{OH} 45229$

USA

E-mail: laura.ramsey@cchmc.org 